\title{
Metodologia ativa na educação médica
}

\author{
Active methodology in medical education
}

\author{
Valter Carabetta Júnior
}

Carabetta Júnior V. Metodologia ativa na educação médica / Active methodology in medical education. Rev Med (São Paulo). 2016 jul.-set.;95(3):113-21.

RESUMO: Na escola médica vem ganhando cada vez mais destaque o discurso sobre a necessidade e importância de que a organização curricular e o conteúdo programático assumam uma proposta interdisciplinar, desvinculando-se da organização curricular fechada, estanque, biologicista, com pouca, ou nenhuma, relação entre as diferentes áreas do conhecimento e ausente de uma visão unificada do corpo humano. Assim, partindo-se do pressuposto de que, em qualquer segmento da escolaridade, o conhecimento é uma construção realizada pelo sujeito cognoscente, e que essa construção depende de estratégias de ensino que tornem os conteúdos significativos aos alunos, neste trabalho são feitas algumas reflexões sobre o papel e o valor da metodologia da problematização como dinâmica possibilitadora de um ensino significativo e interdisciplinar.

Descritores: Educação médica/organização \& administração; Ensino/métodos; Aprendizagem/ética; Aprendizagem baseada em problemas.

$\mathrm{O}$ crescente avanço do conhecimento científico e tecnológico vem transformado rapidamente o mundo, tornando-se cada vez mais notória sua presença no cotidiano social. Tal evolução científica é impulsionada por métodos e conhecimentos de investigação integrados a uma postura científica rigorosa, perspicaz e objetiva que, preparada e desenvolvida ao longo da história, se impõe de maneira inexorável a todos aqueles que pretendem conservar o legado científico do passado ou ampliar suas fronteiras ${ }^{1}$.
ABSTRACT: In medical school is gaining more prominence the speech on the need and importance of the curriculum as well as its organization take an interdisciplinary approach, decoupling closed curricular organization, tighten, biologicist with little, or no relationship among the different areas of knowledge and absent in unified vision of the human body. Thus, starting from the assumption that, in any segment of education, knowledge is a building held by the knowing subject, and that its development depends on teaching strategies that make them meaningful content to students, this work presents some reflections on the role and the value of questioning the methodology as a dynamic enabler of a significant and interdisciplinary teaching.

Keywords: Medical, education/organization and adminstration; Teaching/methods; Learning/ethics;Problem-based.

Diante dessa realidade, o atrativo da ciência na contemporaneidade reside na sua racionalidade explicativa em relação aos diferentes fatos e acontecimentos do mundo e do universo, bem como no desenvolvimento de mecanismos de monitoramento e controle de si mesma e dos processos naturais. Dessa forma, a ciência se estabelece e se reveste de uma autoridade única, pois ao mesmo tempo em que aprofunda conhecimentos sobre a natureza e sobre as relações sociais estabelecidas, proporciona também o desenvolvimento tecnológico que viabiliza o controle sobre

Mestre e Doutor em Educação pela Universidade de São Paulo - FEUSP. Pós-Doutorado em Psicologia da Educação pela PUC/SP. Docente do Curso de Medicina da Universidade de Santo Amaro - UNISA.

Endereço para correspondência: Rua Enéias de Siqueira Neto, 340. CEP: 04829-300 - Jardim das Embúias - São Paulo, SP, Brasil. Email: www.vcarabetta@unisa.br 
a própria natureza e sobre a mudança dessas relações ${ }^{2}$.

Com o objetivo de facilitar o estudo a ciência tornou o conhecimento cada vez mais especializado, culminando por inviabilizar uma visão integrada de fenômenos e situações. Tal modelo científico, racionalista e simplificador, que considera o estudo das partes para entender o todo, departamentalizou o conhecimento em disciplinas isoladas de sua totalidade, validando somente a dimensão do conhecimento baseada em fatos e dados empíricos, já que para executar suas experiências, o sujeito precisa se afastar de seu objeto de estudo para atingir a objetividade $^{3}$.

No caso das ciências da saúde a especialização de conhecimentos fica ainda mais evidente pela desconstrução a que foi submetido o corpo humano, justificada pelo necessário estudo mais complexo de suas partes formadoras, o que dificulta, ou mesmo impossibilita, uma visão holística do ser humano, cujas partes se integram e se inter-relacionam. Tal situação acontece porque na maioria das escolas médicas ainda encontramos uma estrutura curricular atrelada ao modelo flexneriano, caracterizado pela divisão em disciplinas básicas e clínicas, destacandose a importância das especializações e dos departamentos e enfatizando-se os aspectos puramente biológicos.

Devido a crescente fragmentação do conhecimento científico vem ganhando cada vez mais destaque o discurso sobre a necessidade de que a organização curricular e o conteúdo programático desenvolvido nas escolas médicas assumam uma proposta interdisciplinar, desvinculandose de um currículo fechado e estanque, conteudista, biologicista, com pouca, ou nenhuma, relação entre as diferentes áreas do conhecimento e ausente de uma visão unificada do corpo humano.

De acordo com a resolução $n^{\circ} 03$ de 20/06/2014 do Ministério da Educação que institui as Diretrizes Curriculares Nacionais para a graduação em Medicina, no capítulo III: Dos Conteúdos Curriculares e do Projeto Pedagógico do Curso de Graduação em Medicina, o artigo 26 estabelece que o curso deverá ser centrado no aluno como sujeito da aprendizagem e apoiado no professor como facilitador e mediador do processo, com vistas à formação integral e adequada do estudante. Para isso, no art. 29, item II e IV, orienta que o curso deve utilizar metodologias que privilegiem a participação ativa do aluno na construção do conhecimento e na integração entre os conteúdos, assegurando a indissociabilidade do ensino, pesquisa e extensão, bem como promover a integração e a interdisciplinaridade em coerência com o eixo de desenvolvimento curricular.

Tal resolução permite entender a educação em uma perspectiva construtivista, em que a aprendizagem passa a ser caracterizada como uma construção realizada pelo sujeito por meio das relações que estabelece entre as informações que lhe são apresentadas, entre elas com seus conhecimentos prévios e com seu meio social, o que implica uma nova realidade educacional com a ação do aluno para a criação de algo novo por meio do próprio fazer.

No entanto, para uma nova realidade educacional é preciso haver mudança de postura na relação professorconhecimento-aluno, deslocando-se o foco da simples reprodução de conhecimentos para o desenvolvimento de competências e habilidades que devem caminhar junto com a construção do conhecimento socialmente estabelecido com a criação de situações que incentivem constantemente o pensamento dos alunos, cabendo ao professor o papel de "animador da inteligência coletiva do grupo classe" .

Nesse processo, torna-se necessária a conscientização do professor de que ele é o elemento mediador da construção do conhecimento pelos alunos e, para tanto, deve dispor de uma pedagogia que torne a aprendizagem significativa, isto é, que oportunize a interação daquilo que será aprendido com a estrutura cognitiva dos alunos por um processo de assimilação entre antigos e novos significados, visando à diferenciação cognitiva, modificando, assim, os seus esquemas de conhecimento.

Porém, na contramão dos pressupostos de ensinoaprendizagem abordados acima, no ensino universitário ainda persiste o caráter informativo, com transmissão rápida de conhecimentos e centrada na figura do professor, cabendo ao aluno o papel de receptor das informações veiculadas nas diferentes disciplinas. Nesse sentido, Masetto $^{6}$ afirma que

tradicionalmente a sala de aula nos cursos de ensino superior tem-se constituído como um espaço físico e um tempo determinado durante o qual o professor transmite conhecimentos e experiências aos seus alunos. Poderíamos dizer que se trata de um tempo e de um espaço privilegiado para uma ação do professor, cabendo ao aluno atividades como "copiar a matéria", ouvir as preleções do mestre, fazer perguntas e, no mais das vezes, repetir o que o mestre ensinou (p.85).

O fato de o Ensino Superior priorizar a reprodução de conhecimentos já elaborados, ao invés da busca e estruturação de novos conhecimentos, resulta de uma inércia no exercício da crítica epistemológica, a mesma inércia que privilegia comportamentos reprodutivistas em detrimento da busca da reconstrução metodológica contínua ${ }^{7}$.

Na acepção de Severino ${ }^{8}$ a produção do conhecimento na universidade precisa ser fundamentada em um processo de competência técnica, criativa e crítica.

A competência técnica impõe algumas condições lógicas, epistemológicas e metodológicas para a ciência; a exigência de aplicação do método científico, da precisão técnica e do rigor filosófico. A exigência da autonomia e liberdade de criação tem a ver com a atitude, as condições 
de pesquisador; referindo-se à criatividade e ao impulso criador. A criticidade é qualidade da postura cognoscitiva que permite entender o conhecimento como situado num contexto mais amplo e envolvente, que vai além da simples relação sujeito/objeto. É a capacidade de entender que, para além de sua transparência epistemológica, o conhecimento é sempre uma resultante da trama das relações socioculturais (p.120).

Por proporcionar a práxis pela relação entre ensino, pesquisa e extensão, a universidade reverte-se em local da contestação, do rigor no trabalho com conceitos e métodos e técnicas, da inserção rigorosa e crítica de docentes e discentes na esfera da cultura, do pensamento, da imaginação e da sensibilidade, pois como obra de cultura deve procurar “(...) compreender, afirmar e realizar em seu trabalho o sentido mesmo da existência individual e coletiva, da educação, da escola, da universidade, do ensino, do curso, do currículo, do saber, do ensinar, do aprender e da pesquisa"9 (p.47).

No entendimento de Pimenta e Anastasiou ${ }^{10}$, existe certo consenso de que o exercício docente no Ensino Superior não necessita de conhecimentos sobre o processo de ensino e de aprendizagem, bastando que o professor tenha domínio de conhecimentos de sua área específica, pois o que a identifica é a pesquisa e/ou o exercício profissional em seu campo de trabalho, predominando o despreparo docente para atuação em sala de aula.

Nessa configuração, o próprio critério de ingresso na universidade revela que não há preocupação com a formação pedagógica do professor. A exigência legal para a docência restringe-se à formação no nível de graduação ou pós-graduação na área específica profissional em que o docente vai atuar, conforme a categoria funcional em que se dá seu ingresso. $\mathrm{O}$ encaminhamento desses profissionais para o magistério tem sido, na maioria das vezes, uma situação circunstancial ${ }^{11}$.

Diante dessa realidade, na atual sociedade do conhecimento, é preciso uma nova pedagogia na universidade a fim de que os professores assumam a capacidade de construir um tipo de profissionalismo comprometido com a promoção de um aprendizado cognitivo profundo, com a valorização de uma aprendizagem profissional continuada, que aprendam a ensinar de modo diferente de como foram ensinados, que trabalhem e aprendam em parcerias e desenvolvam a capacidade de mudar, arriscar e pesquisar, pois a pedagogia tradicional

(...) já não dá conta de atender às novas demandas de educação (...). A memória, habilidade cognitiva básica nos antigos processos de aprender, é (...) substituída pela capacidade de localizar e mesmo produzir informações e saber trabalhar com elas; em decorrência, os métodos tradicionais tornam-se anacrônicos, exigindo processos de aprender que articulem o mundo da escola ao mundo do trabalho, a teoria à prática, a reflexão à ação, e não apenas como repetição de formas de fazer, mas como formas de produzir concepções transformadoras da realidade (...). A capacidade de aprender um conteúdo determinado é substituída pela competência para continuar aprendendo, como comportamento incorporado de permanente perquirição da realidade; os procedimentos anteriores de avaliação, que objetivavam a verificação da apropriação de conteúdos fragmentados e separados, precisam ser substituídos por procedimentos que verifiquem a capacidade de resolver situações-problema, construindo soluções, a partir da identificação e da organização de informações. Para esta nova concepção de educação, a relação onde o professor era o ator principal em uma cena de monólogo deverá ser substituída por uma relação onde o professor, certamente bem qualificado, organize situações de aprendizagem onde exerça o papel de cúmplice, no estabelecimento de mediações entre o aluno e o conhecimento ${ }^{12}$ (p.7-8).

Nessa linha de pensamento, deve-se assumir, também, que a atuação docente não pode reduzir-se a um trabalho individualista e isolado, mas inserido em uma realidade dinâmica e colaborativa, no qual o diálogo se constitua em aspecto central do planejamento de ensino. A promoção da aprendizagem deve envolver a intencionalidade do planejamento e das ações que sustentem e conduzam uma prática eficiente para atingir objetivos previamente determinados. Um trabalho em que a aprendizagem seja ativa, isto é, construída pelo aluno a partir de interações dialógicas com o professor, com os colegas e com os diferentes conteúdos.

Desse modo, a profissionalização do professor passa a ser estratégica no repensar o Ensino Superior nas dimensões institucional e social ${ }^{13}$. É preciso sustentar a ideia de que o professor deve conhecer as contribuições oferecidas pelas diferentes correntes epistemológicas e teórico-metodológicas para a construção de subsídios da sua prática, tais como: domínio dos conteúdos científicos nos aspectos epistemológicos e históricos, explorando suas relações com o contexto social, econômico e político; questionar visões simplistas de ensino geralmente centradas no modelo transmissão-recepção e na concepção empirista-positivista; saber planejar, desenvolver e avaliar atividades de ensino que contemplem a (re)construção do conhecimento e conceber o cotidiano da sala de aula como objeto de investigação, como ponto de partida e de chegada de reflexões e ações baseadas na articulação teoria-prática ${ }^{14}$, assim como o planejamento e execução de atividades interdisciplinares, rompendo com a visão compartimentalizada do conhecimento.

Para Demo ${ }^{15}$, a compartimentalização da 
universidade foi importante em certa época, pois possibilitou sua democratização e autonomia acadêmica. Porém, tais avanços também trouxeram desvantagens, como: a proliferação de especialidades; a duplicação de disciplinas; o isolamento entre os departamentos; os currículos extensos e, muitas vezes, superficiais; a ausência de comunicação entre cursos e ensino frequentemente desprovido de motivação para o enfrentamento de desafios que, geralmente, são proporcionais ao seu ambiente interdisciplinar.

Frente a atual situação, torna-se prioritário reconhecer o aluno como sujeito do seu conhecimento colocando-o no centro do ensino e viabilizar uma proposta educacional inovadora em que o currículo apresente conteúdos que possam ser trabalhados de modo integrado, desvinculando-se do tradicional ensino fragmentado e especializado, pois a especialização exagerada e sem limites das disciplinas científicas culmina em uma fragmentação crescente do horizonte epistemológico ${ }^{16}$.

Ortega y Gasset ${ }^{17}$ chama a atenção para a fragmentação epistemológica gerada pela especialização, considerando que o

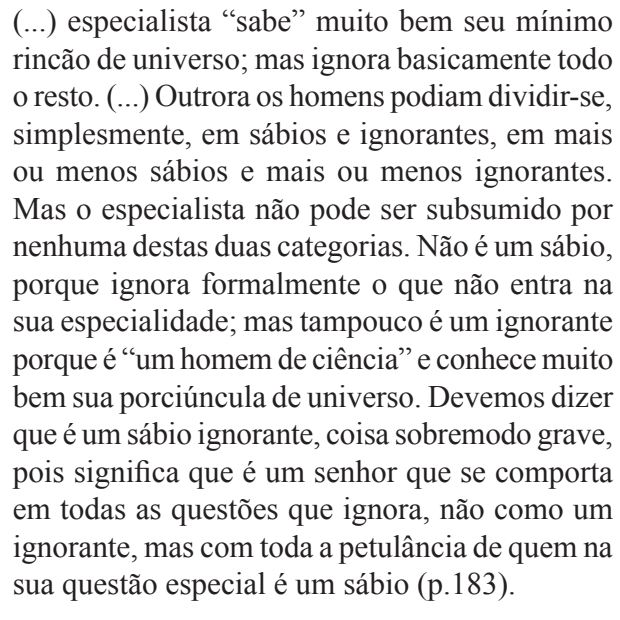

No que tange a escola médica, é primordial o professor pensar na utilização de recursos didáticos que redirecionem o ensino para uma educação alinhada à formação de um médico generalista, com qualificação para compreender o processo saúde-doença, pautando-se em uma postura humana, crítica, reflexiva e ética, desenvolvendo ações nos diferentes níveis de atenção que possibilitem promover a prevenção, recuperação e reabilitação da saúde do ser humano, visando à integralidade da assistência, à responsabilidade social e ao compromisso com a cidadania.

Em consonância com a contemporaneidade, o ensino médico deve ser pensado e organizado de modo a não se enquadrar em velhos modelos de aprendizagem, mas ter a lucidez de encontrar, nas situações concretas, suas potencialidades de formação ${ }^{18}$. Nesse novo cenário, é na ação que o professor demonstra suas capacidades, exercita suas possibilidades atualiza suas potencialidades, revelando, no fazer, o domínio dos saberes e o compromisso com o que é realmente necessário.

Aliada à sólida formação de conteúdos específicos de sua disciplina e ao conhecimento de práticas educacionais, a capacitação e atuação docente também requer um olhar interdisciplinar para estabelecer relações entre os conteúdos da disciplina que leciona com os das outras áreas do conhecimento $^{19}$. De igual modo, é preciso:

(...) formas de raciocínio, de argumentação e de validação; o conhecimento do currículo, incluindo as grandes finalidades e objetivos e a sua articulação vertical e horizontal; o conhecimento do aluno, dos seus processos de aprendizagem, dos seus interesses, das suas necessidades e dificuldades mais frequentes, bem como dos aspectos culturais e sociais que podem interferir positiva e negativamente no seu desempenho escolar; e o conhecimento do processo instrucional, no que se refere à preparação, condição e avaliação da sua prática(...) $(\mathrm{p} .61)^{20}$.

Mas, para assumir uma postura interdisciplinar é preciso considerar o que se entende por interdisciplinaridade para estabelecer a necessária organização disciplinar, os objetivos pretendidos e como a elaboração e viabilização de práticas que a efetivem, superando, dessa maneira, o senso comum de que, para um trabalho interdisciplinar, basta que o professor tenha talento, bom senso, domínio do conteúdo e seguir sua intuição. A categoria fundamental do fazer interdisciplinar é a ousadia ${ }^{21}$, pois a ótica interdisciplinar requer

(...) estruturas flexíveis, mas também implica novos conteúdos articulados em função dos verdadeiros problemas. Enfim, postula métodos fundados menos sobre a distribuição dos conhecimentos que sobre o treinamento de certas aptidões e sobre o desenvolvimento de faculdades psicológicas distintas da memória e do simples raciocínio discursivo ${ }^{16}$ (p. 100).

No parâmetro interdisciplinar, Morin ${ }^{22}$ considera que é apenas o exercício do pensamento complexo sobre uma determinada realidade que poderá proporcionar a reestruturação do pensamento no sentido da contextualização, da articulação e da interdisciplinarização do conhecimento. De acordo com este pensador, a reestruturação

necessária do pensamento é aquela que gera um pensamento do contexto e do complexo. O pensamento contextual busca sempre a relação de inseparabilidade e as inter-retroações entre qualquer fenômeno e seu contexto, e deste com o contexto planetário. O complexo requer um pensamento que capte relações, inter-relações, implicações mútuas, fenômenos multidimensionais, realidades que são 
simultaneamente solidárias e conflitivas (como a própria democracia, que é o sistema que se nutre de antagonismos e que, simultaneamente, os regula), que respeite a diversidade, ao mesmo tempo que a unidade, um pensamento organizador que conceba a relação recíproca entre todas as partes (p.23).

Minayo $^{23}$ destaca que muitos profissionais da educação consideram a interdisciplinaridade como panacéia epistemológica, servindo para solucionar muitos problemas que afetam a consciência científica moderna, e que outros a veem com certo resguardo ou, então, como uma fatalidade própria do avanço científico. A autora chama a atenção para o pensamento de Gusdorf, para quem a prática epistemológica dividida mostra que a excessiva especialização provoca uma esclerose mental, pois o conhecimento deixa de ter relação com o mundo real e dissocia a existência humana. Nesse contexto, o significado da interdisciplinaridade é de um humanismo da pluralidade e da convergência, e toda ciência que se contente em desintegrar e dissociar seu objeto de conhecimento é alienada e alienante.

Desse modo, a proposta interdisciplinar

\begin{abstract}
evoca a "colocação em comum" em lugar da “justaposição dos saberes”, buscando os limites e indo até aos limites das disciplinas, os contornos e os recortes múltiplos, num regime de cooperação e diálogo, abertura e fecundação mútua, sem formalismos que neutralizem as significações. Em nível elementar, a interdisciplinaridade é a primeira exigência de comunicação, pressupondo a inteligibilidade relacional humana. Se cada ciência possui lógica própria, a compreensão desse pluralismo é essencial para uma inteligibilidade diferente (p.49-50).
\end{abstract}

$\mathrm{Pombo}^{24}$ no artigo intitulado "Interdisciplinaridade e integração dos saberes" evidencia quatro termos que se apresentam como mais ou menos equivalentes: pluridisciplinaridade, multidisciplinaridade, interdisciplinaridade e transdisciplinaridade, e que, na maioria das vezes, sentimo-nos perdidos em relação a eles, pois as suas fronteiras não estão claramente definidas para aqueles que os usam, estudam ou tentam defini-los. Chama a atenção para o fato de que em todos eles encontramos uma mesma raiz - a palavra disciplina.

(...) Disciplinas que se pretende juntar: multi, pluri, a ideia é a mesma: juntar muitas, pô- las ao lado uma das outras. Ou então articular, pô-las inter, em inter-relação, estabelecer entre elas uma ação recíproca. $\mathrm{O}$ sufixo trans supõe ir além, uma ultrapassagem daquilo que é próprio da disciplina (p. 05).

Para Pombo, a interdisciplinaridade relacionase a qualquer forma de combinação entre duas ou mais disciplinas, objetivando-se a compreensão de um objeto a partir da confluência de pontos de vista diferentes, e tem como objetivo final a elaboração de síntese relativa ao objeto comum. Nesse sentido, denota que em muitos cursos

(...) são feitas experiências ditas interdisciplinares. Ora, o que acontece é que a palavra está lá, mas percebemos que a experiência em causa é insuficiente que, muitas vezes, se resume a um ato legítimo, por certo, mas de pura "animação cultural". Não de interdisciplinaridade. Quero dizer com isto que a palavra é, pois, ampla demais, que está a ser banalizada, aplicada a um conjunto muito heterogêneo de situações e experiências. E esta utilização excessiva gasta a palavra, esvazia-a, tira-lhe sentido (p.4).

Para a autora supracitada, o mais importante não é a questão nominal: multi, pluri, trans ou interdisciplinaridade, mas compreender o que se pensa e se entende ao evocar tais palavras, destacando que por trás delas está a resistência à especialização, já que “(...) a interdisciplinaridade é o lugar onde se pensa hoje a condição fragmentada das ciências e onde, simultaneamente se exprime a nossa nostalgia de um saber unificado" (p.6).

No entender de Fazenda ${ }^{21}$, a interdisciplinaridade está muito além da simples justaposição de disciplinas ou de conteúdos, requerendo uma atitude diferenciada em relação ao conhecimento, e consolidando-se na busca que é sempre pergunta e pesquisa. Alega que o movimento interdisciplinar permite o estabelecimento de novas e melhores parcerias, pois quando reduzido a ele mesmo se empobrece, e socializado pode adquirir formas diferenciadas e inesperadas.

Independentemente da interpretação assumida por diferentes autores, a interdisciplinaridade sempre será uma reação a uma abordagem disciplinar normalizadora de diferentes objetos de estudo como proposta para superar a fragmentação do conhecimento e a resistência de um saber parcelado, requerendo "equilibrio entre amplitude, profundidade e sintese. A amplitude assegura uma larga base de conhecimento e informação. A profundidade assegura o requisito disciplinar elou conhecimento $e$ informação interdisciplinar para a tarefa a ser executada. A sintese assegura o processo integrador"16 (p.65-6).

Pensando em uma configuração significativa e interdisciplinar para a educação médica, consideramos que, como estratégia de ensino, a metodologia da problematização pode torna-se relevante na proposição de uma orientação para a síntese dos conhecimentos construídos, levando a uma perspectiva de convergência e interação dialética de conhecimentos específicos por meio do diálogo entre os diferentes saberes ${ }^{25}$. Tal metodologia tem como objetivo solucionar problemas por meio de estudos de caso previamente elaborados, em que as ações para seu desenvolvimento partem de um recorte da realidade associada à temática a ser estudada.

A metodologia da problematização encontra-se 
fundamentada nos pressupostos de Paulo Freire, que concebe a educação como um processo incessante e de permanente busca do conhecimento, opondo-se à educação bancária, caracterizada pela falta de criticidade do conhecimento. Na pedagogia problematizadora, o professor deve suscitar nos estudantes o espírito crítico, a curiosidade, a não aceitação do conhecimento simplesmente transferido, tendo como pressuposto de que a aprendizagem acontece com a formulação e a reformulação dos saberes pelos estudantes ao lado dos professores, igualmente sujeitos do processo $^{26}$. Para Freire,

\begin{abstract}
na medida em que o sujeito recebe e arquiva passivamente aquilo que lhe é ensinado, também se torna acomodado, "bestificado". Isso porque a educação bancária "domestica" no sentido de "coisificar" o homem. Assim, a coisificação petrifica e mortifica o espírito ontológico, conforme o pensamento freiriano, na medida em que ele não se descobre enquanto ser inacabado, inconcluso e, portanto, em condição de "ser mais $^{26}$ (p.5).
\end{abstract}

A visão freiriana releva a importância da ação teórico-prática na transformação da realidade e do papel da atividade dialógica na educação, considerando que, mais que um recurso metodológico, a dialogia constitui-se em uma postura política e filosófica frente ao mundo e a existência ${ }^{27}$ porque

(...) pressupõe reconhecer as diferenças, e não os antagonismos entre os interlocutores. São elas - as diferenças - que são capazes de nos apresentar novas e fecundas realidades que questionam os dogmatismos que habitam o nosso próprio discurso, instaurando a possibilidade de uma aprendizagem comum, que se quer em permanente sintonia com o movimento da história (p.32).

Com base em Bordenave e Pereira, Berbel ${ }^{28}$ afirma que a metodologia da problematização é expressão do construtivismo pedagógico e, como tal, compactua certos princípios fundamentais com outros métodos construtivistas, tais como:

parte-se da realidade, com a finalidade de compreendê-la e de construir conhecimento capaz de transformá-la; utiliza-se o que já se sabe sobre a realidade (conteúdos), não como algo absoluto e definitivo nem como um fim em si mesmo, mas como subsídio para encontrar novas relações, novas "verdades", novas soluções; os protagonistas da aprendizagem são os próprios aprendentes. Para isso, acentua-se a descoberta, a participação na ação grupal, a autonomia e a iniciativa; desenvolve-se a capacidade de perguntar, consultar, experimentar, avaliar, características da consciência crítica (p.7).

Para que a configuração da educação problematizadora se torne verdadeira e se efetive, é importante que no fazer pedagógico o professor seja consciente de que uma pessoa só conhece algo quando o transforma, transformando-se ela também no processo e que a solução de problemas implica participação ativa e dialógica entre alunos e professores. Assim, a aprendizagem passa a ser concebida como a resposta natural do aluno ao desafio de uma situação problema, tornando-se uma pesquisa em que passa de uma visão sincrética do problema para uma visão analítica através de sua teorização, para chegar a uma síntese provisória que equivale à compreensão. Dessa apreensão ampla e profunda da estrutura do problema e de suas consequências nascem hipóteses de solução que o obrigam a uma seleção das soluções mais viáveis. A síntese tem continuidade na práxis, isto é, na atividade transformadora da realidade ${ }^{28}$.

Diante do exposto, como estratégia metodológica de estudo e de trabalho, a metodologia da problematização torna-se oportuna nas situações em que os temas estejam relacionados com a vida em sociedade, configurandose nas seguintes etapas: 1) Observação da Realidade: A partir de um tema ou unidade de estudo e sua síntese, com discussões entre o professor e os componentes do grupo que servirá de referência para as outras etapas do estudo; 2) Pontos-Chave: Etapa em que o professor (a) leva os alunos a uma reflexão sobre as possíveis causas da existência do problema em estudo; 3) Teorização: Etapa de estudo e investigação, na qual os alunos devem buscar as informações sobre o problema em estudo; 4) Hipóteses de Solução: Com base nos estudos realizados, elaboração das possíveis soluções para o problema; 5) Aplicação à Realidade: As decisões acordadas nas discussões serão executadas, ou encaminhadas, como compromisso social ${ }^{29}$.

Assim, a metodologia da problematização fornece aos alunos condições para o desenvolvimento de habilidades técnicas, cognitivas e atitudinais de estudar para aprender a aprender, estimulando-lhes a autoformação pela busca constante de informações. Para tanto, a configuração da prática requer a divisão da classe em grupos pequenos, ficando cada grupo com um "professor-tutor" para o desenvolvimento da dinâmica que consiste em: 1) clarificar os termos e conceitos não compreendidos na leitura do problema em estudo; 2) definir o problema; 3) analisar o problema; 4) Desenhar um inventário das explicações inferidas a partir do item 3; 5) Formular objetivos de aprendizagem; 6) Coletar informações adicionais fora do grupo; 7) Sintetizar e testar as informações recém adquiridas $^{28}$.

Nesse caminho, o professor-tutor assume o papel de ativador de esquemas de ação, estimulando, pela dialogia, a participação do grupo: a verificação da relevância dos pontos anotados e comentados pelos alunos; a prevenir o desvio de foco da discussão e de assegurar que o grupo caminhe para atingir os objetivos de aprendizagem, analisando o entendimento do que está sendo discutido. Aos alunos do 
grupo compete o acompanhamento das etapas do processo investigativo; participar das discussões; saber ouvir; respeitar a opinião dos colegas; fazer questionamentos e atividades propostas pelo professor-tutor, procurando, assim, alcançar os objetivos de aprendizagem ${ }^{29}$.

No trabalho pedagógico problematizador é conveniente que em cada encontro o professor-tutor tenha um aluno coordenador, cuja função é de estimular e ajudar o grupo a expor pontos de vista e ordenar o raciocínio, e um aluno relator, que registra as discussões ocorridas na aula, o que ficou acordado pelo grupo e as fontes de pesquisas utilizadas. Ao início de cada trabalho o relator expõe o discutido no encontro anterior para posicionar e direcionar o grupo na sequência investigativa.

Vale ressaltar que em sintonia com os aspectos pedagógicos propostos nas Diretrizes Curriculares Nacionais para Graduação em Medicina, a base psicológica da educação problematizadora é coerente com a epistemologia genética, na qual os indivíduos constituem-se como agentes criadores de seu próprio conhecimento e desenvolvimento, pois considera o sujeito como ser social e em interatividade com um grupo que enfrenta uma situação-problema (etapa sincrética de impacto perceptivo indiscriminado com a realidade); a seguir, fazer com que ele entenda e supere essa indiscriminação (etapa analítica, de tateio assimilativo) para, ao final, solucionar o problema em estudo (etapa sincrética em que há equilíbrio reorganizador das estruturas internas do indivíduo ${ }^{30}$ ).

\section{CONSIDERAÇÕES FINAIS}

Sem a pretensa proposta de generalização, uma vez cientes de que existem opiniões acadêmicas que indicam perspectivas de efetividade (tais como: estimulação da capacidade de investigação científica e conscientização do aluno de sua responsabilidade na construção dos conhecimentos; inter-relacionamento de conhecimentos; aprender a aprender; aprender a fazer; desenvolvimento da capacidade de analisar e interpretar uma situação de modo sistemático; saber utilizar diferentes fontes de informações; construir hipóteses para o problema em análise; desenvolvimento da capacidade de análise, cooperação entre os alunos; respeito e argumentação em relação a opiniões divergentes; dialogar e tomar decisões fundamentadas em evidências técnico-científicas, etc.), e de fragilidade (tais como: insegurança do professor e alunos na nova proposta metodológica; mudança de comportamento e organização; dificuldade de assumir a própria aprendizagem; insegurança na proposição de questionamentos e solução para o problema estudado; desconhecimento pelos alunos de fontes confiáveis e atualizadas para buscar o conhecimento; os conteúdos trabalhados parecem ficar pouco explorados para os alunos, gerando a sensação de que não sabem o que estão aprendendo e onde devem chegar, etc. ${ }^{30}$ ) no uso desse tipo de metodologia no ensino, cremos que a metodologia da problematização, quando devidamente entendida, planejada, articulada entre as diferentes áreas do conhecimento e considerada criticamente suas possibilidades e limitações, pode constituir uma estratégia educacional importante, já que o ponto de partida para a construção do conhecimento é a busca do seu significado mediante a contextualização, a interdisciplinaridade e o incentivo ao raciocínio e a capacidade de aprender.

Nessa abordagem metodológica também é necessário considerar os aspectos relacionados à estrutura curricular do curso; as estratégias planejadas e desenvolvidas para a aprendizagem; o ambiente e os resultados da aprendizagem expressos pela apropriação do discurso acadêmico por estudantes em modos aceitáveis de reflexão e prática sobre um tema de estudo.

As ações educacionais baseadas na metodologia da problematização tornam-se momentos de construção coletiva de conhecimentos por significação, nos quais diferentes situações da realidade observadas e vivenciadas são compartilhadas entre os participantes do grupo, que democratizam saberes, experiências e propostas, sendo a partir dessa prática pedagógica que se pode pensar em uma educação permanente em saúde ${ }^{31}$.

Cabe salientar que, por ser um processo complexo de pensar a educação, a metodologia da problematização requer sólida preparação docente para a superação das barreiras epistemológicas existentes em sua formação e, para tanto, a instituição de ensino deve investir na formação de seus professores para que a ação pedagógica possa ser desenvolvida com conhecimento e segurança, “(...) formação que tome o campo social da prática educativa $e$ de ensinar como objeto de análise, de compreensão, de crítica, de proposição, que desenvolva no professor a atitude de pesquisar, como forma de aprender"32 (p.186).

Essa nova forma de atuar no ensino passa pelo entendimento do professor sobre as especificidades das áreas do currículo, das mudanças vertiginosas do contexto, da rápida implantação e modificação das novas tecnologias da informação, o que requer uma aprendizagem mais operativa, dialógica e menos individualista e funcionalista, aprendizagem fundamentada no diálogo entre aqueles que têm algo a escutar e algo a dizer a quem aprende, implicando em uma nova maneira de ver a formação e atuação docente ${ }^{33}$.

De maneira convergente, os professores precisam construir e assumir um tipo de profissionalismo voltado para: a promoção de um aprendizado profundo; o compromisso de uma contínua aprendizagem profissional; o aprendizado de como ensinar de modo diferente daquele em que foram ensinados; o trabalho em parceria com seus pares; o desenvolvimento da capacidade de mudar, arriscar e pesquisar e para a construção de organizações de aprendizagem na própria instituição ${ }^{32}$.

Depreende-se, assim, que a superação da 
fragmentação do conhecimento só será possível se a sala de aula tornar-se o lugar de um projeto educativo que possa ser entendido como o conjunto articulado de propostas e planos de ação cujas finalidades encontram-se embasadas em valores previamente e devidamente explicitados e assumidos, isto é, com propostas e planos fundamentados em uma intencionalidade como força norteadora da organização e funcionamento da escola derivada de objetivos previamente estabelecidos ${ }^{34}$.

Para finalizar, se a cultura está mudando rapidamente, é necessário repensar a estrutura da instituição escolar, o

\section{REFERÊNCIAS}

1. Cervo AL, Bervian PA, da Silva R. Metodologia científica. São Paulo: Pearson; 2006.

2. Schor T. Reflexões sobre a imbricação entre ciência, tecnologia e sociedade. Rev Scientiae Studia. 2007;5(3):337-67. doi: http://dx.doi.org/10.1590/S1678-31662007000300004.

3. Scalco RF. A ciência moderna e a construção de um saber sócio-espacial [citado 10 jan. 2014]. Disponível em: http:// www.iptan.edu.br/publicacoes/saberes_interdisciplinares/ pdf/revista04/A\%20ciencia\%20moderna.pdf.

4. Brasil. Ministério da Educação. Conselho Nacional de Educação. Câmara de Educação Superior. Resolução CNE/ CES n ${ }^{\circ} 04$ de 07 de novembro de 2001. Institui Diretrizes Curriculares Nacionais do Curso de Graduação em Medicina. Diário Oficial da União. Disponível em: http://portal. mec.gov.br/index.php?option=com_docman\&view=downl oad\&alias=15874rces003-14\&category_slug=junho-2014pdf\&Itemid=30192. Acesso em 05 de jan. de 2016.

5. Levy P. Cibercultura. Rio de Janeiro: Ed. 34; 1999.

6. Masetto MT. Atividades pedagógicas no cotidiano da sala de aula universitária: reflexões e sugestões práticas. In: Castanho S, Castanho ME, organizadores. Temas e textos em metodologia do ensino superior. Campinas: Papirus; 2001.

7. Becker F. Construtivismo: apropriação pedagógica. In: Rosa DER, Souza VC, organizadores. Didática e práticas de ensino: interfaces com diferentes saberes e lugares formativos. Rio de Janeiro: DP\&A; 2002.

8. Severino AJ. Educação e universidade: conhecimento e construção da cidadania. Interface - Comun Saúde Educ. 2002;6(10):117-24. doi: org/10.1590/S141432832002000100015 .

9. Coelho IM. Ensino, pesquisa e formação de estudantes e professores. Campinas: PUC-Campinas; 2004. p.41-59. (Série Acadêmica, 18).

10. Pimenta SG, Anastasiou LGC. Docência no ensino superior. São Paulo: Cortez; 2008.

11. Fernandes CMB. Formação do professor universitário: tarefa de quem? In: Masetto M. Docência na universidade. São Paulo: Papirus; 2009. currículo do curso, as estratégias de ensino, o papel do professor e do aluno, os conteúdos de ensino e os objetivos pretendidos pelo curso e pelas diferentes disciplinas e o aluno que se pretende formar, não apenas para acompanhar as mudanças que ocorrem, mas também para manter a função educativa e formadora da escola, assegurando a formação geral do aluno ${ }^{35}$, pois “(...) as verdaderas innovaciones serán el resultado de las características, necesidades e imaginación local de quienes las hagan... El cambio es parte del proceso educacional. Los métodos van mejorando y seguiremos aprendiendo"36.

12. Kuenze AZ. A formação de educadores no contexto das mudanças no mundo do trabalho: novos desafios para as faculdades de educação [citado 26 mar. 2015]. Disponível em: http://www.educadores.diaadia.pr.gov.br/arquivos/ File/2010/veiculos de comunicacao/EDS/VOL19N63/ EDS ARTIGOS19N̄ 63 - 6.PDF.

13. Batista NA e Batista SH. Desenvolvimento docente em medicina: a prática como elemento estruturante. In: Batista NA, Batista SH, Abdalla YG, organizadores. Ensino em saúde: visitando conceitos e práticas. São Paulo: Arte \& Ciência; 2005

14. Schnetzler R. Práticas de ensino nas ciências naturais: desafios atuais e contribuições de pesquisa. In: Didáticas e práticas de ensino: interfaces com diferentes saberes e lugares formativos. Rio de Janeiro: DP\&A; 2002.

15. Demo P. Conhecimento moderno. Petrópolis: Vozes; 2001.

16. Japiassú H. Interdisciplinaridade e patologia do saber. Rio de Janeiro: Imago; 1976.

17. Gasset JO. A rebelião das massas. Edição eletrônica: Ridendo Castigat Mores [citado 22 nov. 2014]. Disponível em: www.ebooksbrasil.com.

18. Batista SHS. A interdisciplinaridade no ensino médico. Rev Bras Educ Med. 2006;30(1):39-46. http://dx.doi. org/10.1590/S0100-55022006000100007.

19. Rios TA. Competência ou competências: o novo e o original na formação de professores. In: Rosa DEG, Souza VTC, org. Didática e práticas de ensino: interfaces com diferentes saberes e lugares formativos. Rio de Janeiro: DP\&A; 2002; p.154-72.

20. Ponte JP. Didácticas específicas e construção do conhecimento profissional. In: Tavares J, Pereira A, Pedro AP, Sá HA. Investigar e formar em educação. Actas do IV Congresso da Sociedade Portuguesa de Ciência da Educação. Porto: SPCE; 1999.

21. Fazenda I. A virtude da força nas práticas interdisciplinares. São Paulo: Papirus; 1999.

22. Morin E. Educação e complexidade: os sete saberes e outros ensaios. São Paulo: Cortez; 2008.

23. Minayo MC. Interdisciplinaridade: funcionalidade ou 
utopia? Saúde Soc. 1994;3(2):42-64. doi: http://dx.doi. org/10.1590/S0104-12901994000200004.

24. Pombo O. Interdisciplinaridade e integração dos saberes. Liinc Rev. 2005;1(1):3. doi: http://dx.doi.org/10.18617/ liinc.v1il.186.

25. Feuerwerker LCM, Sena RR. Interdisciplinaridade, trabalho multiprofissional e em equipe. Sinônimos? Como se relacionam e o que têm a ver com a nossa vida? Rev Olho Mágico (Londrina). 1999;5(18):24.

26. Fochezatto A, Conceição GH. A proposta da educação problematizadora no pensamento de Paulo Freire. In: IX ANPED Sul-Seminário de Pesquisa em Educação da Região Sul, 2012 [citado 10 mar. 2015]. Disponível em: http://www.portalanpedsul.com.br/admin/uploads/2012/ Filosofia_da_Educacao/Trabalho/02_08_56_1931-75701-PB.pdf.

27. Bauer C. Introdução crítica ao humanismo de Paulo Freire. São Paulo: Sundermann; 2008.

28. Berbel NAN. A metodologia da problematização com o arco de Maguerez: uma reflexão teórico-epistemológica. Londrina: EDUEL; 2012.

29. Berbel NAN. A problematização e a aprendizagem baseada em problemas: diferentes termos ou diferentes caminhos? [citado 21 jun. 2016]. Disponível em: http://www.scielo. br/pdf/icse/v2n2/08.
30. Marin MJS, Lima EFG, Paviotti AB, Matsuyama DT, Silva LKD, Gonzales C, Druzian S, Ilias M. Aspectos das fortalezas e fragilidades no uso de metodologias ativas na aprendizagem. Rev Bras Educ Med. 2010;34(1):13-20. doi: org/10.1590/S0100-55022010000100003.

31. Vasconcelos M, et al. Módulo 4: Práticas pedagógicas em atenção básica à saúde. Tecnologias para abordagem ao indivíduo, família e comunidade. Belo Horizonte: Editora da UFMG 0- Nescon UFMG; 2009.

32. Pimenta SG, Anastasiou LGC. Docência no ensino superior. São Paulo: Cortez; 2008.

33. Imbernón F. Formação continuada de professores. São Paulo: Artmed; 2012

34. Severino AJ. Conhecimento pedagógico e interdisciplinaridade: o saber como intencionalização da prática. In: Fazenda I, organizador. Didática e interdisciplinaridade. São Paulo: Papirus; 1998.

35. Penin STS. Didática e cultura: o ensino comprometido com o social e a contemporaneidade. In: Castro ADC, Carvalho AMPC, organizador. Ensinar a ensinar. São Paulo: Pioneira; 2008 .

36. Venturelli J. Educación médica y en ciencias de la salud; inminencia y necesidad del cambio. [s.1.]: Facultad de Ciencias de la Salud - Universidad de Macmaster; s.d. 